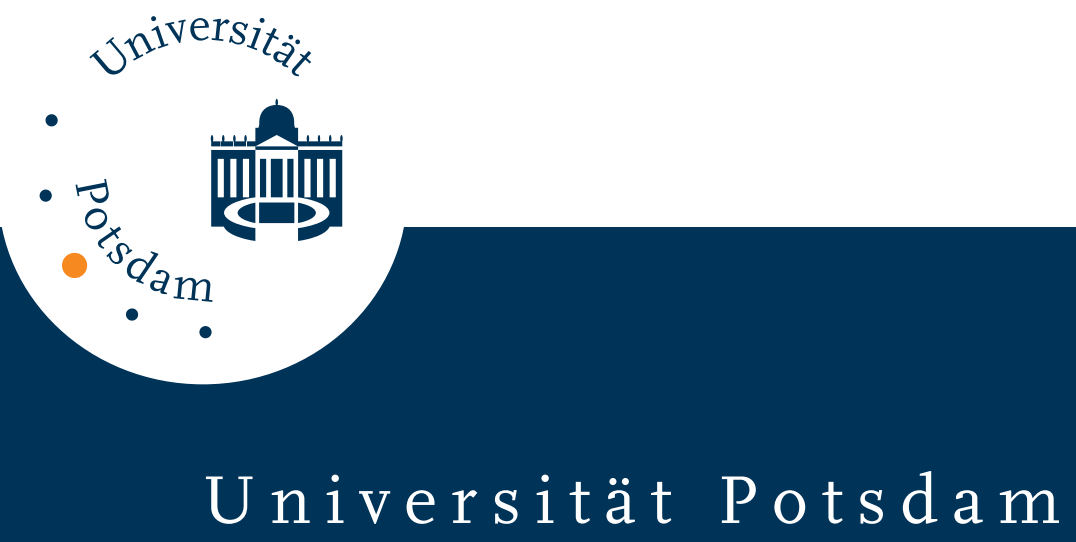

Freya Dittmann-Kohli, Margie E. Lachmann, Reinhold Kliegl, Paul B. Baltes

\title{
Effects of cognitive training and testing on intellectual efficacy beliefs in elderly adults
}

first published in:

Journal of Gerontology 46 (1991) 4, S. 162-164, ISSN 0022-1422,

DOI 10.1093/geronj/46.4.P162

Postprint published at the Institutional Repository of the Potsdam University:

In: Postprints der Universität Potsdam

Humanwissenschaftliche Reihe ; 157

http://opus.kobv.de/ubp/volltexte/2010/4035/

http://nbn-resolving.de/urn:nbn:de:kobv:517-opus-40351

Postprints der Universität Potsdam

Humanwissenschaftliche Reihe ; 157 


\title{
Effects of Cognitive Training and Testing on Intellectual Efficacy Beliefs in Elderly Adults
}

\author{
Freya Dittmann-Kohli,' Margie E. Lachman, ${ }^{2}$ \\ Reinhold Kliegl,' and Paul B. Baltes ${ }^{1}$
}

'Max Planck Institute for Human Development and Education, Berlin, Germany, F.R. and ${ }^{2}$ Brandeis University, Waltham, Massachusetts.

\begin{abstract}
Elderly adults ( $\mathrm{N}=116$; average age $=73$ years) were randomly assigned to one of four treatment groups varying in the amount of training and testing on fluid intelligence tests. They were compared before and after treatment on self-efficacy and utility beliefs for intelligence tests and everyday competence. Although both ability training and extended retest practice resulted in significant gains in objective test performance (Baltes, Kliegl, \& Dittmann-Kohli, 1988), only ability training resulted in positive changes in self-efficacy. However, these changes were restricted to testrelated self-efficacy. Training had no impact on perceived utility or on everyday self-efficacy beliefs. Implications of the results are discussed with regard to interventions to increase intellectual self-efficacy in elderly persons.
\end{abstract}

$\mathrm{A}$ LARGE body of work has demonstrated that there is plasticity in cognitive functioning in later life (Baltes, Kliegl, \& Dittmann-Kohli, 1988; Baltes \& Lindenberger, 1988; Schaie \& Willis, 1986; Willis, 1988). These training studies were conducted largely to examine to what extent cognitive performance could be modified in later life, with particular attention to those cognitive abilities (such as fluid intelligence, memory, and spatial abilities) which had shown the greatest aging-related decrements in longitudinal and cross-sectional studies (Schaie, 1983). In most studies, however, the impact of training on subjective dimensions such as self-efficacy for cognitive tasks or the perceived utility of acquiring new skills has not been investigated. Because subjective assessments of efficacy and utility affect motivation, persistence, affect, and choice of tasks (Bandura, 1989), training effects are unlikely to show maintenance over time or generalizability across tasks unless they are accompanied by changes in self-conceptions that foster effective use of the newly acquired skills (Elliott \& Lachman, 1988). Thus, it is desirable that cognitive training leads not only to increases in performance but also to commensurate changes in self-conceptions about the ability to solve intellectual tasks as well as their subjective value. The present study was conducted to examine whether elderly adults would change their self-efficacy beliefs and perceived utility for intellectual tasks as a function of cognitive training or testing experiences involving tests of intelligence.

\section{METHOD}

Subjects. - One hundred and sixteen (81 female and 35 male) older adults (average age: 73 years; range 63-89 years) from Berlin participated in the study. Health, compared to others similar in age, was rated on a 5-point scale $(1=$ very bad, $5=$ very good $)$, with a mean of $3.8(S D=$ .6). Average educational level was 12 years $(S D=3.0)$, about two years above average for this cohort (Bundesminister fuer Bildung und Wissenschaft, 1988/89).
Measures. - Information about the intelligence test battery can be found in earlier publications (Baltes \& Willis, 1982; Baltes et al., 1988). Self-efficacy and perceived utility were rated for all subtests in the intelligence battery. The tests covered in the training program were two Figural Relations and two Induction subtests, and the untrained tests were the Raven Progressive Matrices, Number Comparison, Identical Pictures, and Vocabulary tests.

For each intelligence subtest, sample items were provided, and subjects were asked ( 6 questions) to estimate their ability to solve such items and the utility of the relevant skills for everyday life on a 6-point Likert scale $(1=$ very poorly or very little; $6=$ very well or very much). Two subscales with three items each were created: self-efficacy (alpha = .97 ) and perceived utility (alpha $=.94$ ). The efficacy items assessed perceived level of performance, potential for further improvement, and assumed ability to train other people. The utility items reflected the perceived usefulness of acquiring test competence for everyday life, and the worthiness and importance of solving the tasks. Retest reliabilities over 6 to 8 weeks were .68 for efficacy and .71 for utility.

Everyday efficacy was assessed with a 31-item scale (coefficient alpha $=.93)$, using a 6 -point Likert scale $(1=$ very poorly; $6=$ very well). The items deal with competence in specific everyday skills and situations (e.g., how well could you remember something for a short while). Stability (6-8 week retest reliability) for the everyday efficacy was .82 .

Design and procedure. - After subjects completed pretest battery of intelligence tests (see Baltes et al., 1988 , for specific information about tests and training conditions), they completed the self-conception questionnaires. Following this assessment, subjects were randomly assigned to one of four groups: (1) pretest-only control; (2) no-contact control; (3) retest control; and (4) ability training. Groups 2, 3, and 4 took the intelligence posttest $6-8$ weeks after the pretest, and all four groups completed self-conception ques- 
Table 1. Means and Standard Deviations for Test-Related Efficacy and Utility by Treatment Group, Test Type, and Testing Occasion

\begin{tabular}{|c|c|c|c|c|c|c|c|c|}
\hline \multirow[b]{3}{*}{ Occasion } & \multicolumn{4}{|c|}{ Trained Tests } & \multicolumn{4}{|c|}{ Untrained Tests } \\
\hline & \multicolumn{2}{|c|}{ Pretest } & \multicolumn{2}{|c|}{ Posttest } & \multicolumn{2}{|c|}{ Pretest } & \multicolumn{2}{|c|}{ Posttest } \\
\hline & $M$ & $(S D)$ & $M$ & $(S D)$ & $M$ & $(S D)$ & $M$ & $(S D)$ \\
\hline \multicolumn{9}{|c|}{ Efficacy } \\
\hline \multicolumn{9}{|l|}{ Treatment group } \\
\hline Pretest-only control & 48.3 & (7.4) & 44.7 & $(10.0)$ & 50.7 & (6.3) & 42.9 & (11.2) \\
\hline No-contact control & 52.2 & (5.2) & 50.1 & $(6.4)$ & 52.7 & $(5.1)$ & 50.5 & $(4.8)$ \\
\hline Retest practice & 50.4 & $(6.5)$ & 48.4 & (6.6) & 49.0 & (9.6) & 47.7 & (7.0) \\
\hline Cognitive training & 48.5 & (9.3) & 51.6 & $(5.9)$ & 48.5 & (7.4) & 48.7 & $(6.5)$ \\
\hline \multicolumn{9}{|c|}{ Utility } \\
\hline Pretest-only control & 49.0 & (8.6) & 47.4 & (10.3) & 50.4 & (9.1) & 44.3 & (11.7) \\
\hline No-contact control & 49.9 & (7.8) & 49.1 & $(9.3)$ & 50.1 & (7.4) & 50.2 & $(6.8)$ \\
\hline Retest practice & 52.3 & (7.1) & 50.4 & (7.5) & 51.8 & (6.6) & 49.5 & (7.5) \\
\hline Cognitive training & 48.1 & (9.3) & 49.7 & (7.4) & 47.9 & (8.9) & 47.4 & (8.8) \\
\hline
\end{tabular}

tionnaires following the posttest. Testing sessions were conducted in large groups; the tests were administered in a standardized way with time limits. No feedback was given about the test results or the solving of individual test items.

Following the pretest, the experimental subjects received 10 sessions of cognitive training in small groups of 6-12, lasting about one hour each. After explanation by a tutor of the principles of task construction and alternative solution strategies for items of Figural Relations and Induction, training participants practiced individually with training materials developed for that purpose (these did not include the actual test items used in the testing; see Baltes \& Willis, 1982). They then shared their results with the group and explained how they had reached the solution. Feedback was given for the correct and incorrect answers. The training was restricted to tasks involving the two fluid abilities. It was not geared toward inducing changes in ability-related beliefs by persuasion or social modeling (see Bandura's, 1977, four factors of efficacy inducement). The retesting group was given the opportunity to practice all of the tests from the pretest/posttest battery for a time comparable to the training sessions. The tests were administered exactly as given at the pretest, over three sessions lasting $3^{1 / 2}$ hours each.

\section{RESULTS}

Cognitive performance. - For cognitive performance, the retesting and ability-trained groups were significantly better than the no-contact control group on the trained tasks. On the untrained tasks, the retest group was significantly better than either the training or control group, but the training group did not differ from the control group. Additional results for intelligence test performance are contained in a different report (Baltes et al., 1988).

Test-related efficacy. - Efficacy and utility scale scores were computed and standardized to T-scores $(M=50, S D=$ 10 ), using the pretest means and standard deviations. This standardization procedure is often used in training studies for ease of comparison across samples and measures and to facilitate the evaluation of the magnitude of change in terms of standard deviation units (Baltes \& Willis, 1982). Differential group changes were analyzed with a 4 (treatment group) $\times 2$ (pre-vs posttest occasion) $\times 2$ (trained vs untrained test) mixed model ANOVA with repeated measures on the last two factors (see Table 1 for means). The group by occasion by test-type effect was significant for Efficacy, $F(3,104)$ $=4.8, p<.004$ and for Utility, $F(3,104)=5.9, p<.001$. Tukey post-hoc tests showed that the ability training group significantly $(p<.01)$ increased their sense of efficacy, and did so significantly $(p<.001)$ more than the other three groups, for the trained tasks, but not for the untrained tasks. In addition, the efficacy beliefs for trained $(p<.001)$ and untrained tasks $(p<.001)$ and the utility beliefs for untrained tasks $(p<.01)$ of the pretest-only control group declined significantly more than the other groups.

Transfer to self-efficacy in everyday activities. - A 4 (treatment group) $\times 2$ (occasion) ANOVA with repeated measures on the last factor was conducted. No group differences were found, although all subjects decreased in their everyday self-efficacy ratings from pretest to posttest, $F(1,104)=7.13, p<.01$.

\section{Discussion}

Cognitive training of fluid intelligence-related skills and testing affects self-conceptions of test-related performance in a differential manner. In general, positive transfer only occurred after cognitive training, even though the retesting group had also significantly improved their cognitive performance. For the training group, increases in efficacy were found, however, only for the trained tests. There was no evidence of transfer to beliefs about everyday cognitive skills and competence, and training did not produce significant gains in perceived utility. Conversely, testing alone produced negative changes in self-efficacy, with a single test session producing the most significant amount of decline. It is not clear whether this decline in self-efficacy signifies the adoption of a more negative view of abilities. However, given the possibility that one-shot group testing without feedback may have negative effects on self-conceptions, 
future studies that involve intelligence testing should examine the impact on self-efficacy, and also consider providing supportive feedback.

Another possible interpretation of the decline in efficacy for the control groups is that it reflects a self-corrective adjustment in self-assessments after further experience with testing. The latter interpretation would be consistent with past self-efficacy research, in which older adults have been found to overestimate their abilities at first and to become more accurate with testing experience (Devolder, Brigham, \& Pressley, 1990; Hertzog, Dixon, \& Hultsch, 1990; Lachman \& Jelallian, 1984). Although the current assessment of efficacy does not allow for a direct analysis of accuracy, a similar process of readjustment could be involved. It is still noteworthy that several of the groups showed increases in objective performance, but only the training group showed increases in self-efficacy. It is possible that the natural tendency is for all groups to overestimate their abilities to begin with and then to readjust self-assessments downward. In contrast, only the training group, which received supportive feedback and explicit confirmation of their performance improvements, surpassed the other groups in self-knowledge about their increased abilities, thereby avoiding decreases in efficacy.

Previous training studies have examined only objective performance, without considering whether training affects subjective assessments of performance. The pattern of results suggests that cognitive training involving tutor-guided, supportive feedback in relevant cognitive skills can result in increases in perceived competence, including confidence in one's own level of functioning, the ability to teach others, and the ability to improve further. These self-conceptions may be relevant for further acquisition of skills and the application of the acquired intellectual abilities.

The results also show that the positive effects of the training experience are restricted to the training context and are not transferred to tests not specifically trained or to selfperceptions of everyday cognitive skills and competencies. This finding is reflected in the results for everyday cognitive efficacy and for the test-specific utility questions, for which there were no positive changes. It appears that the participants did not see the relevance or value of cognitive performance on psychometric test items for their everyday lives.

\section{ACKNOWLEDGMENTS}

We gratefully acknowledge the assistance of Anita Günther, Annet: Rentz, Eva Derge, Peter Grund, Ulrich Mayr, and Karl Wahlen in da. collection and data analysis. Steven Comelius provided helpful comment: on an earlier version of the manuscript.

Address correspondence to Freya Dittmann-Kohli, Max Planck Institute for Human Development and Education, Lentzeallee 94, D-1000 Berlin 33, Germany, F.R.

\section{REFERENCES}

Baltes, P. B., Kliegl, R., \& Dittmann-Kohli, F. (1988). On the locus of training gains in research on the plasticity of fluid intelligence in old age Journal of Educational Psychology, 80, 392-400.

Baltes, P. B., \& Lindenberger, U. (1988). On the range of cognitive plasticity in old age as a function of experience: 15 years of intervention research. Behavioral Therapy, 19, 283-300.

Baltes, P. B., \& Willis, S. L. (1982). Plasticity and enhancement intellectual functioning in old age: Penn State's Adult Development an Enrichment Project (ADEPT). In F. I. M. Craik \& S. E. Trehub (Eds.) Aging and cognitive processes. New York: Plenum Press.

Bandura, A. (1977). Self-efficacy: Toward a unifying theory of behaviora! change. Psychological Review, 84, 191-215.

Bandura, A. (1989). Regulation of cognitive processes through perceived self-efficacy. Developmental Psychology, 25, 729-735.

Bundesminister fuer Bildung und Wissenschaft (Ed.). (1988/89). Grundund Strukturdaten. Bad Honnef: Verlag Bock.

Devolder, P. A., Brigham, M. C., \& Pressley, M. (1990). Memory performance awareness in younger and older adults. Psychology and Aging, 5, 291-303.

Elliott, E., \& Lachman, M. E. (1989). Enhancing memory by modifying control beliefs, attributions, and performance goals in the elderly. In P. S. Fry (Ed.), Advances in psychology: Psychology of helplessness and control in the aged (pp. 339-365). Amsterdam: North Holland.

Hertzog, C., Dixon, R. A., \& Hultsch, D. F. (1990). Relationships between metamemory, memory predictions, and memory task performance in adults. Psychology and Aging, 5, 215-227.

Lachman, M. E., \& Jelallian, E. (1984). Self-efficacy and attributions for young and elderly adults. Journal of Gerontology, 39, 577-582.

Schaie, K. W. (Ed.). (1983). Longitudinal studies of adult psychological development. New York: Guilford Press.

Schaie, K. W., \& Willis, S. L. (1986). Can adult intellectual decline be reversed? Developmental Psychology, 22, 223-232.

Willis, S. L. (1988). Cognitive training and everyday competence. In K. W. Schaie \& C. Eisdorfer (Eds.), Annual review of gerontology and geriatrics (Vol. 7, pp. 159-188). New York: Springer. 